\title{
KIF17 mediates the learning and memory impairment in offspring induced by maternal exposure to propofol during middle pregnancy
}

\author{
LIUQING WU $^{1,2^{*}}$, SHENGQIANG WANG ${ }^{1 *}$, YUNLIN FENG $^{1}$, WEIHONG ZHAO ${ }^{1}$, \\ WEI ZUO ${ }^{3}$, LIANG ZHONG ${ }^{4}$, JIAMEI LIN ${ }^{1}$, WEILU ZHAO ${ }^{1}$ and FOQUAN LUO ${ }^{1}$ \\ ${ }^{1}$ Department of Anesthesiology, The First Affiliated Hospital, Nanchang University, Nanchang, Jiangxi 330006; \\ ${ }^{2}$ Department of Anesthesiology, The Cancer Hospital of Jiangxi Province, Nanchang, Jiangxi 330029; \\ ${ }^{3}$ Department of Pain Management, The People's Hospital of Jiujiang, Jiujiang, Jiangxi 332000; ${ }^{4}$ Department of \\ Anesthesiology, The People's Hospital of Pingxiang, Pingxiang, Jiangxi 337000, P.R. China
}

Received October 6, 2017; Accepted December 15, 2017

DOI: $10.3892 / \mathrm{mmr} .2018 .8479$

\begin{abstract}
Preclinical studies suggest that propofol may cause neuronal injury to the developing brain. A previous study demonstrated that, in a rat model, maternal exposure to propofol during early or late pregnancy caused learning and memory impairment in the offspring. However, whether propofol exposure during middle pregnancy can cause long-term behavioral deficits in the offspring remains to be elucidated. N-methyl-D-aspartate receptor 2B subunit (NR2B) serves a critical role in memory modulation. To exert its function, NR2B must be transported to the neuronal membrane by kinesin family member 17 (KIF17). The aim of the present study was to investigate the role of KIF17 in learning and memory impairment in rat offspring caused by propofol exposure during middle pregnancy. Pregnant rats were exposed to propofol on gestational day 14 (G14) for 4 and $8 \mathrm{~h}$, with control pregnant rats receiving an equal volume of normal saline. The learning and memory of the offspring was assessed using Morris water maze tests from postnatal day 30 (P30) to P36. The levels of KIF17 protein, total NR2B (T-NR2B) and membrane NR2B (M-NR2B) in the hippocampus were detected using western blotting. The results demonstrated that propofol exposure caused learning and memory deficits and decreased KIF17 and M-NR2B protein levels in the hippocampus; however, no but changes in the expression of
\end{abstract}

Correspondence to: Dr Foquan Luo, Department of Anesthesiology, The First Affiliated Hospital, Nanchang University, 17 Yongwai Zheng Street, Nanchang, Jiangxi 330006, P.R. China

E-mail: 1fqjxmc@outlook.com

*Contributed equally

Key words: propofol, middle pregnancy, offspring, learning and memory, N-methyl-D-aspartate receptor 2 subunit B, kinesin family member 17
T-NR2B were observed. These results indicate that maternal propofol exposure during middle pregnancy impairs learning and memory in offspring rats by suppressing the expression of KIF17 and inhibiting the translocation of NR2B to the neuronal membrane.

\section{Introduction}

Increasing evidence has demonstrated that general anesthetic agents may cause long-term impairment to the central nerve system (1). Ikonomidou et al (2) demonstrated that exposure to NMDA receptor blockades, including ketamine, during gestational days 17-19 or postnatal days 3-7 in rats may induce neuronal apoptotic degeneration in the developing brain. Hayashi et al (3) reported that the majority of general anesthetics could cause irreversible cognitive defects associated with neuronal apoptosis.

It has been reported that, when exposed to general anesthetics, the developing brain may experience neuronal apoptosis and long-term defects in learning and memory $(4,5)$. The fetal brain is susceptible to noxious stimulus (6) and $\sim 2 \%$ of pregnant women undergo non-obstetric surgeries during gestation (7), the majority of which are performed under general anesthetic (8). Propofol is one of the most commonly used general anesthetics and easily passes through the placental barrier (9). It has been demonstrated that propofol exposure in early life can cause long-term cognitive deficits (6) associated with impairment of the hippocampal neurons (10). A previous study by our group demonstrated that maternal exposure to propofol in early or late pregnancy impairs learning and memory in rat offspring $(11,12)$. However, the effect of propofol exposure during middle pregnancy remains to be elucidated.

It has been demonstrated that the N-methyl-D-aspartate (NMDA) receptor in the hippocampus serves an important role in the formation and maintenance of learning and memory. The NMDA receptor contains 7 subunits. The functional properties of the NMDA receptor are determined by the NDMA receptor 2B subunit (NR2B) (13). NR2B knockout results in cognitive function impairments, whereas 
transfection with the NR2B gene promotes the formation of long-term potentiation (LTP) and enhances learning and memory in mice $(14,15)$. NR2B must be transported to the neuronal membrane by kinesin family member 17 (KIF17), a neuron-specific molecular motor in neuronal dendrites, in order to serve its function (16). Selective transport is accomplished by direct interaction between the KIF17 tail and a PDZ domain of mLin-10 (Mint1/X11), a constituent of a large protein complex including mLin-2 (CASK), mLin-7 (MALS/Velis) and the NR2B subunit (17). There is an ATP binding site in the head of the molecular motor KIF17, which provides energy for KIF17 to transport NR2B on microtubules (16). When vesicles containing NR2B are transported to the end of dendrite by KIF17, NR2B will be released and bind to the neuronal membrane (18). The release depends on regulation of the calmodulin-dependent protein kinase II (CaMKII) (18). Costa et al (19) reported that the decrease in NR2B/NR2A is associated with KIF17 decline in the Ts65Dn mouse brain. Guillaud et al (20) also demonstrated that NR2B on the synaptic membrane (M-NR2B) decreased with KIF17 decline in mice. KIF17 knockout results in a marked decline of M-NR2B; however, total NR2B (T-NR2B) was not affected (21). This confirms that KIF17 regulates the levels of M-NR2B and affects learning and memory (22).

In the present study, the effects of maternal propofol exposure during middle pregnancy on the expression of KIF17 and NR2B protein, including T-NR2B and M-NR2B, were investigated in order to ascertain the role of KIF17 in learning and memory impairment in offspring rats exposed to propofol during middle pregnancy.

\section{Materials and methods}

Animals. Sprague-Dawley rats (8-9 weeks old; weight, 200-270 g; 34 females and 16 males) were purchased from the Animal Science Research Department of Jiangxi Traditional Chinese Medicine College (JZDWNO, 2011-0030; Nanchang, Jiangxi, China). Rats were housed at $22-25^{\circ} \mathrm{C}$ and $55 \pm 5 \%$ humidity, with a $12 \mathrm{~h}$ light/dark cycle and free access to food and water. Following a Morris water maze (MWM) test, these parental rats that could find the platform no more than once during 6 consecutive days' training trials were excluded (4 females and 1 male). Then 30 female and 15 male parental rats were randomly assigned to control, $\mathrm{P} 4$ and $\mathrm{P} 8$ group. The learning and memory of the parental rats were analyzed and showed no significant difference among three groups $(\mathrm{P}>0.05)$. Propofol infusion for $4 \mathrm{~h}$ (P4), propofol infusion for $8 \mathrm{~h}$ (P8) and saline control $(\mathrm{C})$ groups $(\mathrm{n}=10)$. Female and male parental rats were housed together to allow for mating ( 2 females per male). All protocols were approved by the institutional review board of the First Affiliated Hospital of Nanchang University on the Use of Animals in Research and Teaching.

Propofol exposure. On gestational day 14 (G14), $20 \mathrm{mg} / \mathrm{kg}$ of propofol (200 mg/20 ml; AstraZeneca, Basiglio, Italy) was injected into pregnant rats in the propofol exposure groups via the caudal vein at a rate of $20 \mathrm{mg} / \mathrm{kg} / \mathrm{h}$ of continuous infusion for 4 or $8 \mathrm{~h}$. The dose of propofol was selected based on a previous study (12). Equal volumes of saline were administered to rats in the control group. The propofol infusion time was selected for a number of reasons; i) a previous study (12) demonstrated that neuronal damage is highest when general anesthetic exposure time is between 6 and $8 \mathrm{~h}$, whereas $2 \mathrm{~h}$ exposure has no significant difference; ii) the majority of surgical procedures require $2-4 \mathrm{~h}$ of anesthesia or more; and iii) our previous study (12) demonstrated that maternal exposure to propofol (at the same dosage used in present study) for $2 \mathrm{~h}$ during early gestation had no significant effect on learning and memory in rat offspring, whereas exposure for 4 or $8 \mathrm{~h}$ caused significant impairments without affecting the levels of blood gases in pregnant rats.

Electrocardiograms, saturation of pulse oximetry $\left(\mathrm{SpO}_{2}\right)$ and tail non-invasive blood pressure were monitored during propofol exposure. If $\mathrm{SpO}_{2}$ was $<95 \%$ and/or the systolic blood pressure was $<80 \%$ of baseline for $>5 \mathrm{~min}$, the rat was removed from the study and another pregnant rat was selected to replace it, thereby preventing toxicity from maternal ischemia or hypoxia in rat offspring.

Blood gases analysis. To determine whether propofol exposure at G14 causes disturbances in maternal blood gases, blood was harvested from the caudal vein at the end of propofol anesthesia and was analyzed using a blood gas analyzer (ABL77; Radiometer Medical ApS, Brønshøj, Denmark) for $\mathrm{pH}$, partial pressure $(\mathrm{P}) \mathrm{O}_{2}, \mathrm{PCO}_{2}, \mathrm{HCO}^{-}, \mathrm{Na}^{+}, \mathrm{K}^{+}, \mathrm{Ca}^{2+}$, and base excess.

$M W M$. Spatial memory and learning were assessed in rat offspring using an MWM system (Beijing Sunny Instruments Co., Ltd., Beijing, China) beginning on postnatal day 30 (P30) as previously described (11). The trials began at 9:00 am on each testing day. The MWM is a black circular steel pool (diameter $=50 \mathrm{~cm}$ and height $=60 \mathrm{~cm}$ ) that was filled with water at $24 \pm 1^{\circ} \mathrm{C}$. A platform was hidden $1 \mathrm{~cm}$ below the water surface in the second (target) quadrant of the MWM system. Each rat was put into the pool and allowed to search for the platform once per day for 6 consecutive days. The time taken for the rats to find the platform was recorded as escape latency (learning ability). If they were able to find the platform within $120 \mathrm{sec}$, rats were allowed to stay on the platform for $30 \mathrm{sec}$. However, if a rat did not find the platform within $120 \mathrm{sec}$, it was guided to the platform and allowed to remain there for $30 \mathrm{sec}$, with the escape latency recorded as $120 \mathrm{sec}$. On day 7, the platform was removed. The rats were then allowed to perform the spatial probe test (memory test) for $120 \mathrm{sec}$. The number of times that the rat swam across the site where the platform was hidden (platform-crossing times) and the duration spent in the target quadrant (target quadrant time) were recorded using a video connected to a computer (ZH0065; Beijing Sunny Instruments Co., Ltd., Beijing, China). The mean value of the latencies, platform-crossing times and target quadrant times of offspring born to the same mother were calculated as the final results.

Hippocampus harvest. The day following the spatial probe test, rats were sacrificed by cervical dislocation. Hippocampus tissues of offspring were harvested and stored at $-80^{\circ} \mathrm{C}$ for western blot analysis.

Western blot analysis. Total hippocampus protein was extracted by homogenizing hippocampal tissues $(n=10$ from 

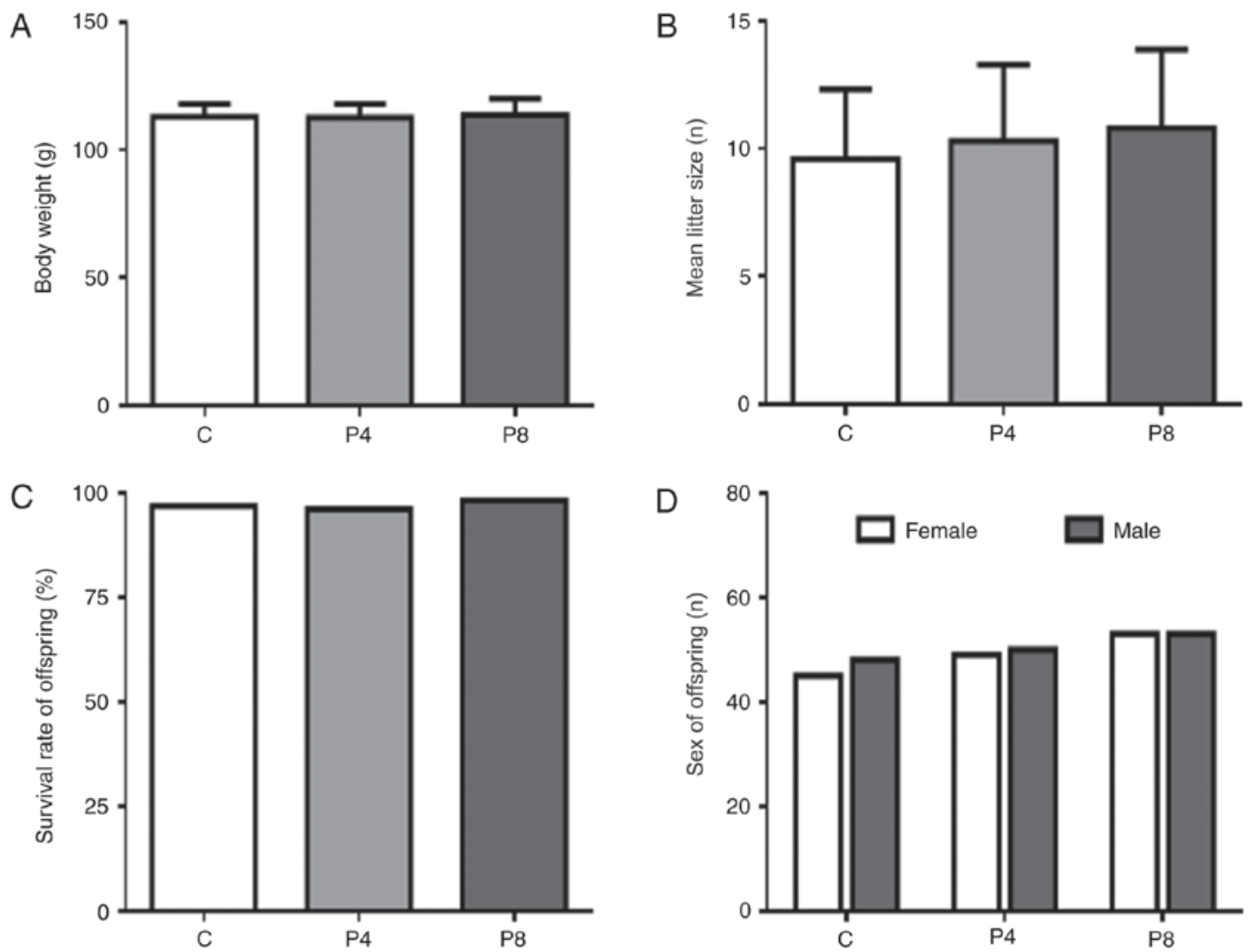

Figure 1. Physical features of the offspring. Comparisons of (A) body weight, (B) total number, (C) survival rates and (D) sex ratio in the offspring of rats exposed to propofol during middle pregnancy. C, control; P4, propofol exposure for $4 \mathrm{~h}$; P8, propofol exposure for $8 \mathrm{~h}$.

each group) in lysis buffer (78510; Thermo Fisher Scientific, Inc., Waltham, MA, USA) containing a protease inhibitor cocktail (Sigma-Aldrich; Merck KGaA, Darmstadt, Germany). The hippocampal membrane protein was extracted using a membrane protein extraction kit (E231-01; Vazyme Biotech Co., Ltd., Nanjing, China) according to the manufacturer's protocol. Protein concentrations were determined using a bicinchoninic acid protein assay (Bio-Rad Laboratories, Inc., Hercules, CA, USA). A total of $50 \mu \mathrm{g}$ protein/lane was separated by $8 \%$ SDS-PAGE and transferred onto a polyvinylidene fluoride membrane. The membranes were blocked with a $5 \%$ non-fat dry milk buffer at room temperature for $1 \mathrm{~h}$ and then incubated overnight at $4{ }^{\circ} \mathrm{C}$ with the following primary antibodies: rabbit polyclonal anti-KIF17 (sc-50455; 1:2,000; Santa Cruz Biotechnology, Inc., Dallas, TX, USA), rabbit polyclonal anti-NR2B (4207S; 1:500; Cell Signaling Technology, Inc., Danvers, MA, USA), rabbit polyclonal anti- $\beta$-actin (T0022-25UG; 1:2,000; Affinity Biosciences, Cambridge, UK) and anti-Na ${ }^{+} / \mathrm{K}^{+}$ATPase antibody (ab33655; 1:2,000; Abcam, Cambridge, MA, USA). The membranes were incubated with horseradish peroxidase-conjugated polyclonal anti-IgG antibody (HS101-01; 1:500; Beijing TransGen Biotech Co., Ltd., Beijing, China) and developed using a SuperSignal ${ }^{\mathrm{TM}}$ West Pico PLUS Chemiluminescent Substrate (34577; Thermo Fisher Scientific, Inc., Waltham, MA, USA). Images were scanned using an Image Master II scanner (GE Healthcare, Chicago, IL, USA) and the optical densities of bands were quantitatively analyzed by using ImageJ 1.38 (National Institutes of Health, Bethesda, MD, USA). The results were expressed relative to $\beta$-actin or $\mathrm{Na}^{+} / \mathrm{K}^{+}$ATPase.
Statistical analysis. Data are presented as the mean \pm standard deviation. SPSS version 17.0 software (SPSS, Inc., Chicago, IL, USA) was used to analyze the data. The escape latency was analyzed by repeated measurement two-way analysis of variance with prenatal treatment as between-subjects independent factors and day as repeated factors with the least significant difference post hoc test. Data from protein and blood gases were analyzed by one-way analysis of variance with the least significant difference post hoc test. $\mathrm{P}<0.05$ was considered to indicate a statistically significant difference.

\section{Results}

Physical features of the offspring. On day P30, no significant differences in mean body weight were observed between the control and propofol exposure groups (Fig. 1A). Propofol exposure in middle pregnancy had no significant effect on birth rate, offspring survival rate or sex ratio (Fig. 1B-D, respectively). Maternal propofol exposure also had no evident influence on physical development of offspring. Dyskinesia was not observed in either of the three groups. These results indicate that propofol exposure on day G14 does not affect offspring survival, sex or basic physical development, which suggests that the differences in learning and memory observed in the present study were induced by maternal propofol exposure rather than physical differences.

Blood gases. To investigate whether propofol exposure on day G14 causes disturbances in maternal blood gases, caudal vein blood was collected from pregnant rats following propofol 
Table I. Blood gases in pregnant rats ( $\mathrm{n}=10$; mean \pm standard deviation).

\begin{tabular}{lrrr}
\hline Parameter & Control group & P8 group & P-value \\
\hline $\mathrm{pH}$ & $7.36 \pm 0.13$ & $7.35 \pm 0.19$ & 0.290 \\
$\mathrm{PO}_{2}(\mathrm{mmHg})$ & $46.33 \pm 3.65$ & $44.50 \pm 5.59$ & 0.140 \\
$\mathrm{PCO}_{2}(\mathrm{mmHg})$ & $53.70 \pm 4.12$ & $51.79 \pm 9.67$ & 0.146 \\
$\mathrm{HCO}_{3}^{-}(\mathrm{mmol} / \mathrm{l})$ & $29.43 \pm 1.19$ & $26.31 \pm 3.37$ & 0.220 \\
$\mathrm{BE}(\mathrm{B})(\mathrm{mmol} / \mathrm{l})$ & $3.41 \pm 0.87$ & $3.53 \pm 1.12$ & 0.558 \\
$\mathrm{Ca}^{2+}(\mathrm{mmol} / \mathrm{l})$ & $1.33 \pm 0.12$ & $1.41 \pm 0.26$ & 0.520 \\
$\mathrm{~K}^{+}(\mathrm{mmol} / \mathrm{l})$ & $4.35 \pm 0.71$ & $4.61 \pm 0.63$ & 0.631 \\
$\mathrm{Na}^{+}(\mathrm{mmol} / \mathrm{l})$ & $136.71 \pm 1.78$ & $135.12 \pm 1.52$ & 0.518 \\
\hline
\end{tabular}

P, partial pressure; BE, base excess; P8, propofol infusion for $8 \mathrm{~h}$.

A
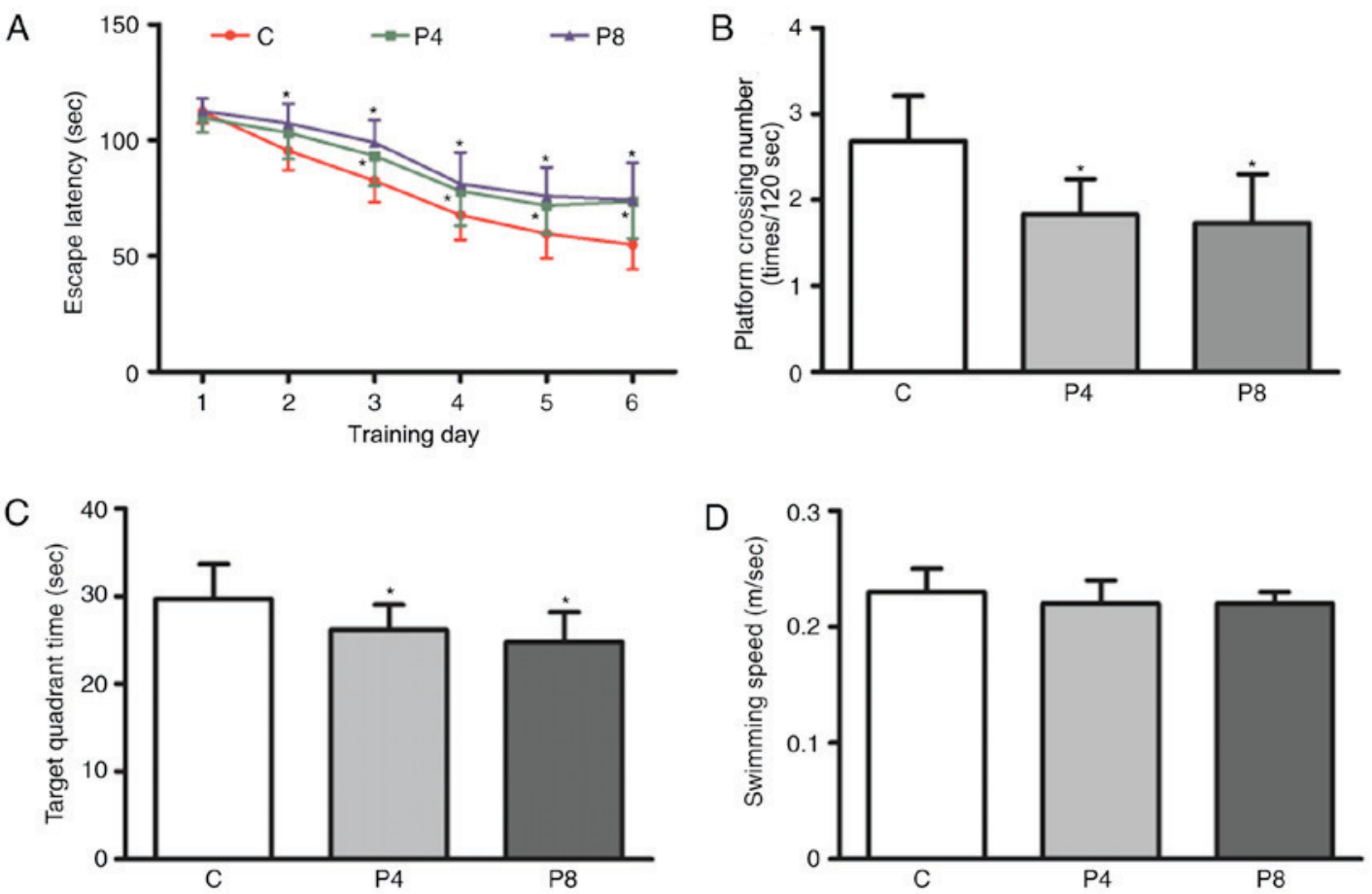

Figure 2. Effects of exposure to propofol in middle pregnancy on learning and memory in offspring rats. A Morris water maze test was performed and (A) escape latency, (B) platform crossing number, (C) target quadrant time and (D) swimming speed were recorded. "P $>0.05$ vs. C group. C, control; P4, propofol exposure for $4 \mathrm{~h} ; \mathrm{P} 8$, propofol exposure for $8 \mathrm{~h}$.

anesthesia. No significant differences in blood gases were observed between the propofol exposure and control groups (Table I). These results suggest that the differences in learning and memory observed in the present study were induced by maternal propofol exposure rather than internal environment disturbance in pregnant rats.

The body temperature, heart rate, respiratory rate, blood pressure and $\mathrm{SPO} 2$ of maternal rats were monitored during propofol infusion. No significant differences were identified in these indexes

Impaired learning and memory in offspring. The results of the MWM test demonstrated that the escape latency of rats in $\mathrm{P} 4$ and $\mathrm{P} 8$ groups was significantly prolonged compared with the $\mathrm{C}$ group $(\mathrm{P}<0.05$; Fig. $2 \mathrm{~A})$. The escape latency in the $\mathrm{P} 8$ group was longer compared with the $\mathrm{P} 4$ group, although no significant difference was observed between the two groups (Fig. 2A). The platform-crossing times and target quadrant time in the $\mathrm{P} 4$ and $\mathrm{P} 8$ groups were significantly lower compared with the $\mathrm{C}$ group $(\mathrm{P}<0.05$; Fig. $2 \mathrm{~B}$ and $\mathrm{C})$ and were slightly lower in the P8 group compared with the P4 group (Fig. 2B and C). No significant difference in swimming speed was observed between the 3 groups (Fig. 2D). Taken together, these data suggest that exposure of pregnant rats to propofol induced learning and memory impairments in rat offspring.

Decreased KIF17 protein levels in the hippocampus of offspring rats. Expression of KIF17 and NR2B in the hippocampus of offspring rats was assessed using western blotting (Fig. 3). Levels of KIF17 protein in the hippocampus of offspring rats in the $\mathrm{P} 8$ and $\mathrm{P} 4$ groups were significantly decrease compared with the $\mathrm{C}$ group $(\mathrm{P}<0.05$; Fig. $3 \mathrm{~A}$ and $\mathrm{B})$. 
A

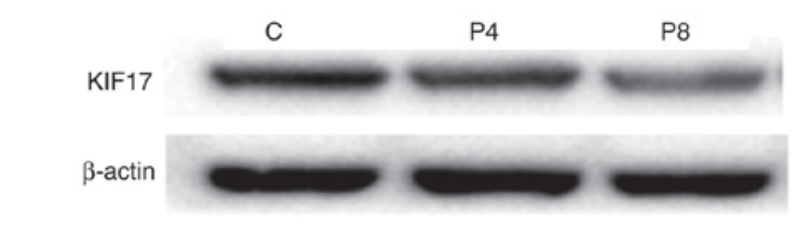

C

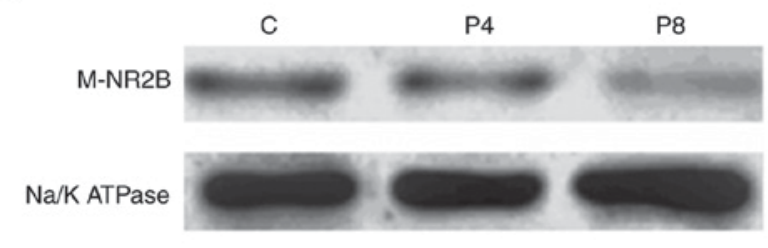

E

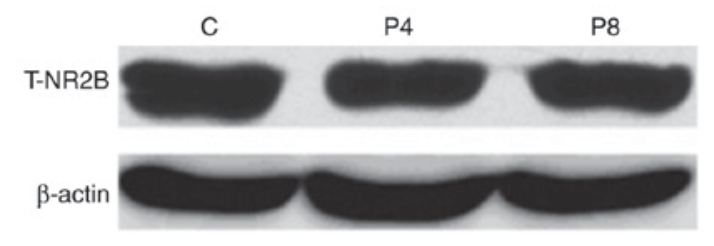

B
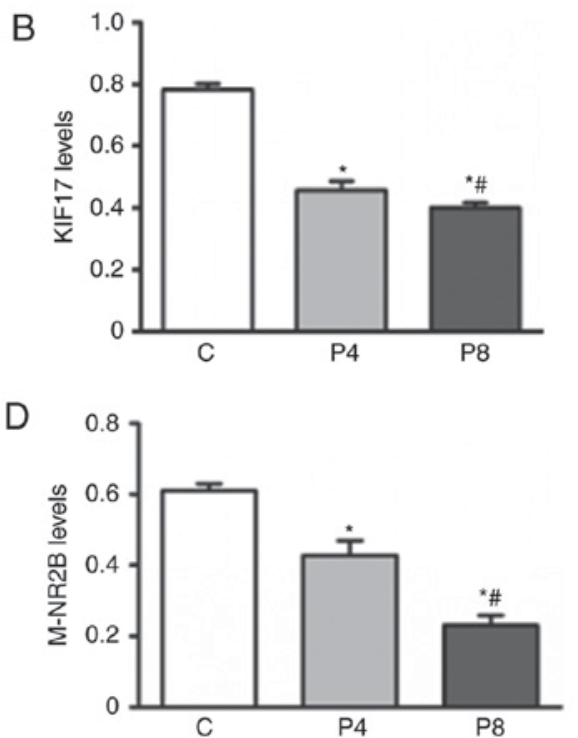

$\mathrm{F}$

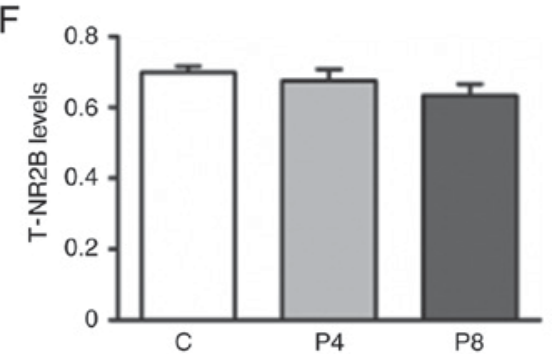

Figure 3. Expression of KIF17 and NR2B in the hippocampus of offspring rats was assessed using western blotting. KIF17 protein expression was assessed using (A) western blotting and (B) quantified. M-NR2B protein expression was assessed using (C) western blotting and (D) quantified. T-NR2B protein expression was assessed using (E) western blotting and (F) quantified. "P>0.05, vs. C and ${ }^{\#} \mathrm{P}>0.05$ vs. P4. KIF17, kinesin family member 17; NR2B, N-methyl-D-aspartate receptor 2B subunit; M-NR2B, membrane protein of NR2B; T-NR2B, total protein NR2B; C, control; P4, propofol exposure for 4 h; P8, propofol exposure for 8 h.

The expression of KIF17 protein in the P8 group was significantly lower compared with $\mathrm{P} 4$ group $(\mathrm{P}<0.05$; Fig. $3 \mathrm{C}$ and $\mathrm{B})$, suggesting that pregnant rat exposure to propofol decreases the expression of KIF17 protein in the hippocampus of offspring rats.

Decreased levels of $M-N R 2 B$ were observed in propofol treatment groups. No significant differences in the hippocampus expression of T-NR2B protein were identified between the three groups (Fig. 3E and F). However, the expression of M-NR2B was significantly lower in group P8 compared with group $\mathrm{P} 4$ and expression in group $\mathrm{P} 4$ was significantly lower compared with group $\mathrm{C}(\mathrm{P}<0.05$; Fig. $3 \mathrm{D}$ and $\mathrm{E})$. These results suggest that propofol-induced learning and memory impairments in offspring are associated with a decrease in M-NR2B protein in the hippocampus,

Correlation analysis. The levels of M-NR2B in the hippocampus of offspring rats were positively correlated KIF17 expression $(\mathrm{r}=0.877 ; \mathrm{P}=0.001)$, which suggests that $\mathrm{KIF} 17$ serves a role in transporting NR2B to its target cell membrane.

\section{Discussion}

The results of the present study demonstrate that exposure to propofol during middle pregnancy causes learning and memory defects as well as decreased hippocampal expression of KIF17 and M-NR2B in offspring rats. The body temperature, heart rate, respiratory rate, blood pressure and $\mathrm{SPO}_{2}$ of maternal rats were monitored during propofol infusion. No significant changes were identified in these indexes. Blood gases were analyzed following propofol infusion and no significant changes were observed. Therefore, the learning and memory impairments observed in the present study were not due to pathological disorders. Propofol had no significant effect on the physical development of the offspring and no significant differences in body weight or dyskinesia were observed between the groups, suggesting that the learning and memory impairments were induced by maternal propofol exposure rather than physical differences. These results are similar to a previous study, in which it was reported that propofol infusion on day G18 caused brain damage and permanent learning and memory dysfunction in offspring rats (1).

Preclinical evidence has demonstrated that general anesthetic agents may accelerate apoptosis and inhibit the proliferation of neuron progenitor cells, thus causing irreversible neurological damage to receptors $(23,24)$. Combined use of two or more anesthetic agents resulted in more severe damage compared with a single anesthetic alone $(25,26)$. Propofol is able to induce neuronal apoptosis in young rats and cause brain dysfunction by activating the $\gamma$-aminobutyric acid receptor $(27,28)$. Neonatal or juvenile exposure to propofol 
has been reported to cause learning and memory impairments in adult rats by inducing neurodegeneration and a reduction in the expression of neurotransmitters and brain-derived neurotrophic factor (BDNF) (29-33). In addition, prolonged exposure to propofol in aged rats also causes long-term learning and memory impairment $(34,35)$. An in vitro study demonstrated that propofol damages the neural structure in a dose-dependent manner (36).

Our previous study demonstrated the offspring of pregnant rats exposed to anesthesia for $2 \mathrm{~h}$ had no deficit in learning and memory; however, prolonged exposure of $4 \mathrm{~h}$ could resulted in significant impairments (12). The second trimester is regarded as the safest period during pregnancy and the majority of non-obstetric surgeries are performed during this period under general anesthesia $(37,38)$. However, the effect of maternal exposure to propofol during the second trimester on the learning and memory in offspring remains to be elucidated. The results of the present study demonstrate that exposure to propofol caused learning and memory impairment in offspring rats. It is therefore necessary to consider the underlying mechanisms responsible.

NMDA receptors are divided into 7 subunits, of which NR2B is the most important for learning and memory formation (39). NR2B gene knockout causes changes in synaptic plasticity and serious deficits in learning and memory, whereas NR2B overexpression is beneficial for LTP, thus promoting learning and memory $(14,15)$.

The combination of phosphorylated cyclic adenosine monophosphate response element (cAMP) binding protein (CREB) with the cAMP response element on NR2B will increase the expression of NR2B $(40,41)$, and then NR2B will potentiate the transcription of memory related-downstream genes, including immediate early genes $c$-fos and $c$-jun. Transcription of these genes potentiates synaptic reconstruction, promotes LTP and inhibits long-term depression in the hippocampus, thus affecting learning and memory development $(42,43)$. In the present study, maternal propofol exposure during middle pregnancy significantly decreased the expression of M-NR2B protein in the hippocampus of offspring rats, whereas T-NR2B expression was unaffected. These data suggest that maternal propofol exposure during the second trimester may impair learning and memory in offspring by inhibiting NR2B transport to the neuronal membrane as opposed to inhibiting the expression of NR2B in the hippocampus. This is possible as NR2B protein must be transported to the cell membrane in order to perform its regulatory function in learning and memory (44). It is necessary to consider how maternal propofol exposure may inhibit transportation of NR2B to the neuronal membrane.

KIF17, a kinetic protein that is responsible for the transportation of NR2B to the cell membrane by combining with the vesicle via Mint-1 protein, moves along the microtubules towards the cell membrane (17). Vesicles containing NR2B are released into the dendritic cell membrane to exert learning and memory regulating functions $(17,18)$. Previous studies have demonstrated that KIF17 expression may affect the levels of M-NR2B and thus influence synaptic plasticity and cognition $(21,22)$. Yin et al (44) confirmed that KIF17 (-/-) mice lost the ability to transport NR2B, resulting in a decrease in NR2B in the synaptic membrane and causing impaired synaptic plasticity and spatial memory. The results of the present study demonstrated that to propofol for 4 and $8 \mathrm{~h}$ during middle pregnancy decreased the expression of KIF17 in the hippocampus of offspring rats, which was associated with a downregulation in M-NR2B.

In the present study, KIF17 and M-NR2B expression was significantly lower in the $\mathrm{P} 8$ group compared with the $\mathrm{P} 4$ group, whereas no significant differences in learning and memory were observed between the 2 groups. Memory includes spatial memory, recognition memory, episodic memory, emotional memory and semantic memory. Though the MWM test is recognized as a useful for assessing memory in rodents, it mainly reflects spatial learning and memory (45). In addition, the learning and memory tasks in the MWM test are relatively simple. To overcome this limitation, multiple behavioral tests, including open field test, fear conditioning test and object recognition tests should be used in future studies.

Although learning and memory are mainly regulated by the hippocampus, other areas of the brain, including the cerebral cortex, serve an important role (46). In order to gain a more comprehensive understanding of the underlying mechanisms of memory defects, changes in KIF17 and NR2B in other cerebral areas should be investigated in future studies. Our previous study demonstrated that propofol exposure during late gestation impaired the learning and memory of rat offspring via the BDNF- tropomyosin receptor kinase B (TrkB) pathway (11). Interactions between the BDNF-TrkB signaling pathway and NR2B serve a critical role in memory (47). However, whether the BDNF-TrkB signaling pathway serves a role in the learning and memory defects induced by maternal exposure to propofol during middle pregnancy requires further investigation.

In conclusion, maternal propofol exposure during middle pregnancy may impair learning and memory function in offspring rats by suppressing the expression of KIF17 in the hippocampus, thus inhibiting translocation of NR2B to the cellular membrane. This suggests KIF17 may be a potential therapeutic target for the memory deficits in offspring caused by maternal propofol exposure.

\section{Acknowledgements}

The present study was supported by the National Natural Science Foundation of China (grant no. 81460175) and the Natural Science Foundation of Jiangxi Province of China (grant no. 20171ACB20030).

\section{References}

1. Xiong M, Li J, Alhashem HM, Tilak V, Patel A, Pisklakov S, Siegel A, Ye JH and Bekker A: Propofol exposure in pregnant rats induces neurotoxicity and persistent learning deficit in the offspring. Brain Sci 4: 356-375, 2014.

2. Ikonomidou C, Bosch F, Miksa M, Bittigau P, Vöckler J, Dikranian K, Tenkova TI, Stefovska V, Turski L and Olney JW: Blockade of NMDA receptors and apoptotic neurodegeneration in the developing brain. Science 283: 70-74, 1999.

3. Hayashi H, Dikkes P and Soriano SG: Repeated administration of ketamine may lead to neuronal degeneration in the developing rat brain. Paediatr Anaesth 12: 770-774, 2002.

4. Jevtovic-Todorovic V and Olney JW: PRO: Anesthesia-induced developmental neuroapoptosis: Status of the evidence. Anesth Analg 106: 1659-1663, 2008.

5. Loepke AW and Soriano SG: An assessment of the effects of general anesthetics on developing brain structure and neurocognitive function. Anesth Analg 106: 1681-1707, 2008. 
6. McGowan FX Jr and Davis PJ: Anesthetic-related neurotoxicity in the developing infant: Of mice, rats, monkeys and, possibly, humans. Anesth Analg 106: 1599-602, 2008.

7. Van De Velde M and De Buck F: Anesthesia for non-obstetric surgery in the pregnant patient. Minerva Anestesiol 73: 235-240, 2007.

8. Baldwin EA, Borowski KS, Brost BC and Rose $\mathrm{CH}$ : Antepartum nonobstetrical surgery at $\geq 23$ weeks' gestation and risk for preterm delivery. Am J Obstet Gynecol 212: 232.e1-e5, 2015.

9. Chidambaran V, Costandi A and D'Mello A: Propofol: A review of its role in pediatric anesthesia and sedation. CNS Drugs 29 543-563, 2015 .

10. Krzisch M, Sultan S, Sandell J, Demeter K, Vutskits L and Toni N: Propofol anesthesia impairs the maturation and survival of adult-born hippocampal neurons. Anesthesiology 118: 602-610, 2013.

11. Zhong L, Luo F, Zhao W, Feng Y, Wu L, Lin J, Liu T, Wang S, You X and Zhang W: Propofol exposure during late stages of pregnancy impairs learning and memory in rat offspring via the BDNF-TrkB signalling pathway. J Cell Mol Med 20: 1920-1931, 2016.

12. Zhang Q, Luo F, Zhao W, Li B, Tang Y and Hu Y: Effect of prolonged anesthesia with propofol during early pregnancy on cognitive function of offspring rats. Chin J Anesthesiol 34: 1051-1053, 2014.

13. Williams JM, Guévremont D, Kennard JT, Mason-Parker SE, Tate WP and Abraham WC: Long-term regulation of N-methyl$\mathrm{D}$-aspartate receptor subunits and associated synaptic proteins following hippocampal synaptic plasticity. Neuroscience 118 : 1003-1013, 2003.

14. Niimi K, Takahashi E and Itakura C: Improved short-term memory and increased expression of NR2B observed in senescence-accelerated mouse (SAM) P6. Exp Gerontol 43: 847-852, 2008.

15. von Engelhardt J, Doganci B, Jensen V, Hvalby $\varnothing$, Göngrich C Taylor A, Barkus C, Sanderson DJ, Rawlins JN, Seeburg PH, et al: Contribution of hippocampal and extra-hippocampal NR2Bcontaining NMDA receptors to performance on spatial learning tasks. Neuron 60: 846-860, 2008.

16. Yildiz A and Selvin PR: Kinesin: Walking, crawling or sliding along? Trends Cell Biol 15: 112-120, 2005

17. Setou M, Nakagawa T, Seog DH and Hirokawa N: Kinesin superfamily motor protein KIF17 and mLin-10 in NMDA receptor-containing vesicle transport. Science 288: 1796-1802, 2000 .

18. Guillaud L, Wong R and Hirokawa N: Disruption of KIF17-Mint1 interaction by CaMKII-dependent phosphorylation: A molecular model of kinesin-cargo release. Nat Cell Biol 10: 19-29, 2008.

19. Costa AC, Scott-McKean JJ and Stasko MR: Acute injections of the NMDA receptor antagonist memantine rescue performance deficits of the Ts65Dn mouse model of Down syndrome on a fear conditioning test. Neuropsychopharmacology 33: 1624-1632, 2008.

20. Guillaud L, Setou M and Hirokawa N: KIF17 dynamics and regulation of NR2B trafficking in hippocampal neurons. J Neurosci 23 131-140, 2003.

21. Yin X, Takei Y, Kido MA and Hirokawa N: Molecular motor KIF17 is fundamental for memory and learning via differential support of synaptic NR2A/2B levels. Neuron 70: 310-325, 2011.

22. Wong RW, Setou M, Teng J, Takei Y and Hirokawa N: Overexpression of motor protein KIF17 enhances spatial and working memory in transgenic mice. Proc Natl Acad Sci USA 99: 14500-14505, 2002

23. Dong C, Rovnaghi CR and Anand KJ: Ketamine alters the neurogenesis of rat cortical neural stem progenitor cells. Criti Care Med 40: 2407-2416, 2012.

24. Tang XM, Qin Y, Liao CJ, Xie YB and Lan YY: Effects of propofol on expression of hippocampal survivin and Caspase-3 in newborn rats. Zhonghua Er Ke Za Zhi 50: 361-365, 2012 (In Chinese).

25. Schubert H, Eiselt M, Walter B, Fritz H, Brodhun M and Bauer R: Isoflurane/nitrous oxide anesthesia and stress-induced procedures enhance neuroapoptosis in intrauterine growth-restricted piglets. Intensive care Med 38: 1205-1214, 2012.

26. Zou X, Liu F, Zhang X, Patterson TA, Callicott R, Liu S, Hanig JP, Paule MG, Slikker W Jr and Wang C: Inhalation anesthetic-induced neuronal damage in the developing rhesus monkey. Neurotoxicol Teratol 33: 592-597, 2011
27. Pain L, Angst MJ, LeGourrier L and Oberling P: Effect of a nonsedative dose of propofol on memory for aversively loaded information in rats. Anesthesiology 97: 447-453, 2002.

28. Kahraman S, Zup SL, McCarthy MM and Fiskum G: GABAergic mechanism of propofol toxicity in immature neurons. J Neurosurg Anesthesiol 20: 233-40, 2008.

29. Karen T, Schlager GW, Bendix I, Sifringer M, Herrmann R, Pantazis C, Enot D, Keller M, Kerner T and Felderhoff-Mueser U: Effect of propofol in the immature rat brain on short- and long-term neurodevelopmental outcome. PLoS One 8: e64480, 2013.

30. Yu D, Jiang Y, Gao J, Liu B and Chen P: Repeated exposure to propofol potentiates neuroapoptosis and long-term behavioral deficits in neonatal rats. Neurosci Lett 534: 41-46, 2013.

31. Chen B, Deng X, Wang B and Liu H: Persistent neuronal apoptosis and synaptic loss induced by multiple but not single exposure of propofol contribute to long-term cognitive dysfunction in neonatal rats. J Toxicol Sci 41: 627-636, 2016.

32. Yu D, Li L and Yuan W: Neonatal anesthetic neurotoxicity: Insight into the molecular mechanisms of long-term neurocognitive deficits. Biomed Pharmacother 87: 196-199, 2017.

33. Lee JE, Rayyan M, Liao A, Edery I and Pletcher SD: Acute dietary restriction acts via TOR, PP2A, and Myc signaling to boost innate immunity in Drosophila. Cell Rep 20: 479-490, 2017.

34. Bekker AY and Weeks EJ: Cognitive function after anaesthesia in the elderly. Best Pract Res Clin Anaesthesiol 17: 259-272, 2003.

35. Culley DJ, Baxter M, Yukhananov R and Crosby G: The memory effects of general anesthesia persist for weeks in young and aged rats. Anesth Analg 96: 1004-1009, table of contents, 2003.

36. Vutskits L, Gascon E, Tassonyi E and Kiss JZ: Clinically relevant concentrations of propofol but not midazolam alter in vitro dendritic development of isolated gamma-aminobutyric acid-positive interneurons. Anesthesiology 102: 970-976, 2005.

37. Tran KM: Anesthesia for fetal surgery. Semin Fetal Neonatal Med 15: 40-45, 2010.

38. Reddy SV: Effect of general anesthetics on the developing brain. J Anaesthesiol Clin Pharmacol 28: 6-10, 2012.

39. Zhao MG, Toyoda H, Lee YS, Wu LJ, Ko SW, Zhang XH, Jia Y, Shum F, Xu H, Li BM, et al: Roles of NMDA NR2B subtype receptor in prefrontal long-term potentiation and contextual fear memory. Neuron 47: 859-872, 2005.

40. Dalle S, Quoyer J, Varin E and Costes S: Roles and regulation of the transcription factor CREB in pancreatic $\beta$-cells. Curr Mol Pharmacol 4: 187-195, 2011.

41. Suzuki A, Fukushima H, Mukawa T, Toyoda H, Wu LJ, Zhao MG, $\mathrm{Xu} \mathrm{H}$, Shang Y, Endoh K, Iwamoto T, et al: Upregulation of CREB-mediated transcription enhances both short- and long-term memory. J Neurosci 31: 8786-8802, 2011.

42. Barco A, Alarcon JM and Kandel ER: Expression of constitutively active CREB protein facilitates the late phase of long-term potentiation by enhancing synaptic capture. Cell 108: 689-703, 2002.

43. Pittenger C, Huang YY, Paletzki RF, Bourtchouladze R, Scanlin H, Vronskaya S and Kandel ER: Reversible inhibition of CREB/ATF transcription factors in region CA1 of the dorsal hippocampus disrupts hippocampus-dependent spatial memory. Neuron 34: 447-462, 2002.

44. Yin X, Feng X, Takei Y and Hirokawa N: Regulation of NMDA receptor transport: a KIF17-cargo binding/releasing underlies synaptic plasticity and memory in vivo. J Neurosci 32: 5486-5499, 2012.

45. Vorhees CV and Williams MT: Assessing spatial learning and memory in rodents. ILAR J 55: 310-332, 2014.

46. He J, Zhao C, Liu W, Huang J, Liang S, Chen L and Tao J: Neurochemical changes in the hippocampus and prefrontal cortex associated with electroacupuncture for learning and memory impairment. Int J Mol Med 41: 709-716, 2018.

47. Nakai T, Nagai T, Tanaka M, Itoh N, Asai N, Enomoto A, Asai M, Yamada S, Saifullah AB, Sokabe M, et al: Girdin phosphorylation is crucial for synaptic plasticity and memory: A potential role in the interaction of BDNF/TrkB/Akt signaling with NMDA receptor. J Neurosci 34: 14995-15008, 2014. 